\title{
Imaginar la ciudad: miradas exploratorias en torno a la construcción de las imágenes en los planes estratégicos de Rosario en los años 1998 y 2008
}

To imagine the city: exploratory looks concerning the construction of images in Rosario's strategic plans from 1998 and 2008

Ma. Virginia Esparza ${ }^{1}$

\section{Filiación}

Universidad Nacional de Rosario (UNR), Argentina

Email: mv_esparza1@hotmail.com

Primera versión recibida en: 11 de noviembre de 2013

Última versión recibida en: 19 de diciembre de 2014

\section{Resumen}

El siguiente artículo presenta una reconstrucción de los imaginarios urbanos que se proyectan en los Planes Estratégicos de 1998 y 2008, desarrollados para la ciudad de Rosario, ubicada en el sur de la provincia de Santa Fe, Argentina. Asimismo se establece a la ciudad como objeto de estudio, contextualizando el trabajo realizado en el marco de la tradición teórica urbanística actual y sus desarrollos más importantes en América Latina. Metodológicamente, se comparan ambos Planes Estratégicos y se indagan dos de los principales periódicos de la ciudad de Rosario, como fuentes para considerar el contexto de surgimiento de los mismos. Por último, el análisis de la incidencia de los imaginarios en la creación de espacios públicos, demuestra la construcción de un perfil de ciudad centrada en su acceso al río y la participación de los usuarios a la hora de la apropiación de los mismos.

\section{Palabras claves}

Plan Estratégico, Imaginarios urbanos, Espacio público.

\begin{abstract}
The present paper intends to lay out an interpretation about the Strategic Plans developed in Rosario City (located in the south of Santa Fe province, Argentina) in 1998 and 2008. Our research concerning the city should be understood in the context of contemporary urban studies and its leading exponents in Latin America. The method of our choice has been to compare both strategic plans and inquire for the conditions of its emergence through two of the most important papers in the city. Finally, we would like to conclude, based on the correlations between social imaginary and public space, the city has endorsed a depiction of itself centered on its proximity to the river and the use of that benefit from de citizens.
\end{abstract}

\section{Key words}

Strategic plan, Urban Imaginary, Public space.

\footnotetext{
1 El siguiente trabajo fue impulsado en el marco de la beca de estudiante, auxiliar en investigación otorgada por el programa de Bienestar Estudiantil de la Universidad Nacional de Rosario (UNR), Argentina. El mismo fue desarrollado dentro de una de las líneas de investigación del Centro de Estudios Culturales y Urbanos (CECUR) dirigido por el Dr. Diego Roldán.
} 


\section{Sumario}

Introducción

1 El nuevo papel de lo local

2 Algunas consideraciones sobre el Plan Estratégico Rosario de 1998

$3 \quad$ PER + 10: un accionar redireccionado

4 El imaginario urbano en los planes estratégicos: la constitución de una ciudad como marca

Reflexiones finales

Bibliografía

Fuentes

Planes Estratégicos

Libros y artículos

\section{Introducción}

El resurgimiento de los espacios urbanos como puntos geográficos centrales para la vida social data desde principios de la modernidad. A pesar de enmarcarse en un proceso histórico cuyo comienzo puede rastrearse varios siglos atrás, el ritmo vertiginoso de los cambios que se ha producido en las ciudades durante los últimos dos siglos han modificado sus escenarios y actividades al punto de merecer constituirse en un objeto específico de estudio por parte de las ciencias sociales contemporáneas. Se puede decir que las teorías urbanas que intentan dar una respuesta a lo que la ciudad es, se desarrollaron profundamente en la segunda mitad del s. XX y generaron una multiplicidad de interpretaciones en ese sentido. Así, en los últimos años del s. $X X$, comenzaron a darse nuevas formas de analizar y ver a la ciudad, concentradas en aspectos que van más allá de lo material. Es por esto que, para hacer una reconstrucción de las visiones sobre la ciudad de Rosario, provincia de Santa Fe, Argentina, que forman parte del imaginario urbano proyectado en los diferentes planes estratégicos de la localidad, nos parece importante comenzar por delinear algunos conceptos que determinan a la ciudad como objeto de estudio, y las diferentes formas de verla que se dan hacia finales del s. XX y principios del s. XXI.

El surgimiento de teorías urbanas supuso una definición de su objeto que marcó toda una tradición disciplinar, y que encontramos exhibida con claridad en sus primera producciones. El concepto clásico se basó en elementos distintivos como la cantidad de población, la densidad física y la oposición con el campo a partir de la presencia de actividades de tipo industrial. Siguiendo lo que nos dice Néstor García Canclini sobre esta definición, podemos ubicar a autores como Gino Germani o Louis Wirth dentro de esta tradición, ya que el primero hablaba de la ciudad como núcleo de la modernidad en donde se dan lazos anónimos opuestos a los familiares propios del campo, y el segundo la definió como una localización permanente relativamente extensa y densa de individuos socialmente heterogéneos ${ }^{2}$. Lo que se dejó de lado en estas concepciones no fue secundario. Las definiciones no apelaban a la dimensión subjetiva, ya que se centraban en lo material y lo visible, a partir de criterios morfológicos, económicos y demográficos.

2 GARCÍA CANCLINI, 1997; 70. 
Haciendo frente a la estrechez de la noción tradicional, una renovada generación de teóricos urbanistas de fines del s. XX, comenzaron a centrarse en el estudio del aspecto subjetivo que hacen a las urbes, concentrándose específicamente en el análisis de los imaginarios urbanos. A la necesidad de estudiar otros elementos de las ciudades, se le sumó como impulso un proceso de recentralización urbana que se da en la década del 80, manifestándose a través de un retorno a los centros citadinos, en oposición a la dispersión hacia los suburbios, vivida en los 60 .

En este contexto de renovación científica urbanística podemos estudiar la morfología que tiene la visión dominante sobre la ciudad de Rosario, para luego analizar cómo este imaginario urbano forma parte del ideario político y es trasladado a las políticas urbanísticas desarrolladas en Rosario a partir del Plan Estratégico Rosario (en adelante PER) de 1998, y en el Plan Estratégico Rosario Metropolitana (en adelante PER + 10) de 2008 - 2018. Además, nos concentramos en la incidencia de las visiones urbanas en la creación y constitución de los espacio públicos, intentando demostrar la participación de los usuarios a la hora de resignificarlos, traspasando los objetivos de la planificación.

Por último, metodológicamente se realiza una comparación de ambos planes, sumando el estudio de los comentarios que los principales diarios de la ciudad, La Capital y El Ciudadano presentaron durante todo el proceso de construcción y promoción de las dos instancias de planificación.

\section{El nuevo papel de lo local}

Para poder comprender el nuevo rol que la ciudad de Rosario ha obtenido en los últimos años del s. XX, debemos analizar primero el contexto mundial y nacional en el que las urbes pasan a tener un papel central en el desarrollo político y económico. $Y$, en especial, las políticas implementadas por el gobierno socialista que asumió al poder en 1989, y aún se mantiene en él, cuyos principales referentes son los políticos Hermes Binner, Miguel Lifschitz y Antonio Bonfatti.

Para Edward Soja en su libro Postmetrópolis, en la década del 60, se hace evidente una crisis urbana que comenzó a desafiar el orden urbano capitalista establecido, caracterizado por la metrópolis moderna fordista - keynesiana generando un cambio radical en estas formas de estructuración del espacio. Así, como producto de este proceso, para fines del s. XX comienza a surgir metrópolis postmoderna, postfordista y postkeynesiana que él denominará postmetrópolis. El autor aclara, que esta nueva forma de organización no se establece por fuera de la industrialización y el capitalismo. No es post - industrial ni post - capitalista, si no representa una metamorfosis que se viene desarrollando a nivel urbano pero no rompe completamente con las formas anteriores si no que las integra en su seno con las nuevas dinámicas.

A la vez, la postmetrópolis se trata del algo completamente nuevo y diferente. La representación de la postmetrópolis no sólo como un modelo arquetípico del desarrollo social y económico contemporáneo, sino también como una realidad metafísica, un lugar donde lo real y lo imaginario se entremezclan ${ }^{3}$. Se genera en ella un cambio profundo en cuanto a lo que la ciudad representa, una importante reestructuración de lo simbólico y de los discursos en que se manifiestan imágenes sobre lo urbano, no siendo solamente una reconfiguración espacial.

Por su parte, García Canclini habla de un retorno a las ciudades que se da en la década del 80 , en oposición al proceso de crisis citadino que se dio en los 60. Desde finales del s. XX muchas metrópolis mundiales han tenido una fuerte recuperación económica, junto con proyectos de renovación urbana y transformaciones físicas. Se produce, entonces, el pasaje de las ciudades a

3 SOJA, 2008; 217. 
las megaciudades, que implican grandes conjuntos urbanos que han conurbado, que han interactuado con otras ciudades y las han incorporado ${ }^{4}$.

Además, las ciudades de finales del s. XX, eran parte de las economías nacionales, eran las unidades básicas en las que se reproducían las relaciones sociales de producción. Al ser la ciudad sólo una célula productiva le dejaba un lugar de centralidad al Estado que había tenido un fuerte accionar en la mayor parte del s. XX. Pero va a ser el neoliberalismo el que, al proyectar el achicamiento del Estado, rompa con el nexo que ubicaba a las ciudades en un papel secundario de mera administración.

Se van a establecer nuevas formas relacionales entre las ciudades y la economía global que van de la mano de una acelerada restructuración mundial. Por esto, las primeras dejarán de ser meras reservas de trabajo para las economías nacionales, pasando a ser, plataformas de producción para las economías globales ${ }^{5}$. En este largo proceso de redefinición del espacio urbano, que se producirá luego de la crisis y a partir de tendencias mundiales de reconfigurar el capitalismo globalizado, se dará una nueva lógica en la organización de los niveles de estatalidad que van a permitir reposicionar a la ciudad como un espacio de importantes relaciones de poder y no como el espacio en donde se tomaban sólo decisiones administrativas.

La ciudad pasará a ser un objeto de estudio en sí mismo. Su abordaje se convirtió en una temática novedosa y necesaria para generar un marketing urbano que formará parte esencial de las futuras planificaciones. La mercantilización de la ciudad impondrá la necesidad de construir una marca de ciudad que condense ciertos rasgos identitarios a resaltar. El marketing urbano tendrá la importante tarea de vender esa nueva mercancía al exterior, para atraer inversiones y turistas, y al interior, para generar legitimación.

Las ciudades se vieron obligadas a posicionarse en el mercado mundial como centros de negocios, cultura y turismo. Comienzan a proliferar zonas de comercios, turismo e industrias, reformando definitivamente los espacios urbanos, orientándolos hacia una economía global para buscar en ella su posicionamiento. De esta manera, el intento por responder a las tendencias globalizadoras implicó una rearticulación de lo local que generó una competencia entre ciudades a escala nacional e internacional. Lo local, en tanto lugar de la praxis que resignifica y articula los procesos globales, devino no sólo objeto de consideración por parte de jurisdicciones mayores si no sujeto creador de pautas para la acción ${ }^{6}$.

La Argentina y específicamente la ciudad de Rosario no fueron ajenas a este proceso. Por eso se hace necesario comprender que, el nuevo papel de las ciudades de Argentina en la década del 90 y de principios del 2000, viene inexorablemente ligado a la reforma de la Constitución Nacional en 1994. La nueva Carta Magna Nacional va establecer un novedoso apartado sobre el gobierno provincial en el que especifica, en el artículo 123, que: Cada provincia dicta su propia Constitución conforme a lo dispuesto por el artículo $5^{\circ}$ asegurando la autonomía municipal (... $)^{7}$. Antes de 1994 no estaba reconocida de ninguna forma la autonomía municipal. Esto creó una gama de derechos y obligaciones de los cuales serían titulares, ahora los municipios y otorgando una renovada y amplia esfera de acción a los gobiernos de las ciudades*.

En este contexto surge en 1998 el PER diseñando las líneas de accionar consideradas centrales y necesarias para posicionar a Rosario internacionalmente y el PER +10 , a 10 años del primero

${ }^{4}$ GARCÍA CANCLINI, 1997; 77.

${ }^{5}$ SMITH, 2013; 15.

${ }^{6}$ POLIMENE, 2009; 86.

7 El resaltado es propio de la autora.

* Párrafo aparte merece el tratamiento de la autonomía de la ciudad de Rosario, que debido a la extensión del artículo no puede desarrollarse. Por referencias en el PER + 10 dirigirse a Rosario Autónoma y Federal. PLAN ESTRATÉGICO ROSARIO METROPOLITANA 2008 - 2018; 148. 
para una evaluación de los logros anteriores y el restablecimiento de nuevas estrategias de acción.

Si bien ambos documentos se concentran en la estrategias para la planificación, el PER, al ser el primero es mucho más extenso y contiene un marco teórico ampliamente desarrollado que nos permite analizar cómo se considera este nuevo papel de la ciudad. Especifica la necesidad de hacer de Rosario una ciudad moderna y de considerarla como un laboratorio privilegiado ${ }^{8}$ en donde el gobierno amplíe su capacidad de actuación. Además, entre los rasgos distintivos del PER, se establece la articulación de lo local y lo global, que implica la capacidad de la ciudad de determinar sus estrategias para incorporarse a los procesos globales.

\section{Algunas consideraciones sobre el Plan Estratégico Rosario de 1998}

Para finales del mes de octubre de 1998 se presentó en forma definitiva el PER, un documento en formato de libro, que daba cuenta de un proceso de planificación iniciado en octubre de 1996. El Plan incluía 72 proyectos de diferente índole diagramados por la Junta Promotora creada para tal fin y debatidos durante esos dos años por más 150 instituciones de la ciudad. Cuando el PER fue presentado muchos de los ejes de trabajo que planteaba ya estaban siendo realizados, no sólo por el gobierno municipal, sino también por el provincial, nacional, o por empresas privadas.

Desde sus primeras páginas el PER es definido como una herramienta de gestión de la ciudad, que no debe ser considerado como una receta o como un manual ${ }^{9}$, dejando ver la concepción que sus promotores tienen del mismo. Supone una definición de manera consciente del uso y orientación que se tendrá de los recursos urbanos. Una estrategia es la creación de un proyecto a seguir, asignando y dividiendo el uso, en el tiempo, de los bienes materiales disponibles, encaminado al desarrollo de manera integral de la sociedad local. Es una herramienta que busca cambiar la realidad orientándola hacia un objetivo determinado, un proyecto global de ciudad que intenta llevarse a cabo. Justamente, en sus propias páginas el PER define a la planificación estratégica como un producto, un documento con coherencia técnica y metodológica, y como un proceso, devenido de un construcción colectiva y social. La planificación estratégica urbana permite incorporar los principales temas de la ciudad y su área metropolitana a una agenda común de políticas públicas, fortaleciendo la gestión local mediante la articulación entre los actores estatales, sociales y del sector privado para coordinar acciones sobre el territorio ${ }^{10}$.

Como antecedentes directos del PER, analizaremos brevemente el conjunto de planes estratégicos que se dan en la ciudad de Barcelona en la década de los 90, con el objetivo de constituir a la ciudad en una metrópolis europea moderna con influencia en la región, mejorando la calidad de vida y cultura de sus habitantes. Como Barcelona fue en 1992 sede de los Juegos Olímpicos, se buscó mantener el impulso generado por este evento y comenzar a construir, sobre las infraestructuras creadas con tal fin, un proyecto de ciudad que fuera más allá del evento deportivo.

El modelo barcelonés de planificación fue tomado y transferido a muchas ciudades latinoamericanas por medio del Centro Iberoamericano de Desarrollo Estratégico Urbano (CIDEU) al cual Rosario pertenece desde agosto de 1995. Si bien esta incorporación es vista por el socialismo como el punto fundacional de los planes estratégicos rosarinos, la historiadora Paula Polimene en su trabajo Ideas globales, problemas locales, se ha encargado de demostrar que la relación con estas formas europeas de desarrollo urbano, se dieron con anterioridad a esa fecha, debido a que desde el gobierno municipal, que por entonces estaba bajo la conducción del

8 PLAN ESTRATÉGICO ROSARIO 1998; 14.

${ }^{9}$ Op. Cit.; 5.

10 PLAN ESTRATÉGICO ROSARIO METROPOLITANA 2008 - 2018; 32. 
peronismo, se estaba discutiendo la posibilidad de una planificación. Además plantea que los vínculos necesarios para realizar una readaptación del modelo barcelonés, no se generaron únicamente desde que el municipio ingresó al CIDEU, si no que las pautas relacionales se conformaron a partir de la asistencia de líderes socialistas a congresos urbanísticos europeos, con anterioridad a 1995.

Retomando esta idea, se hace necesario desmitificar la relación directa que se establece entre el socialismo como fuerza política gobernante y la planificación. Aun cuando posteriormente la referencia que se pueda tener del PER está íntimamente relacionada con este partido político, no se debe dejar de ver que la idea de su creación es anterior a la llegada de Hermes Binner a la Intendencia de la ciudad de Rosario. Por esto, la reivindicación del PER como propio del gobierno socialista generó rispideces, ya que socialistas y peronistas buscaron establecer la imagen de promotores iniciales del mismo. Los entredichos de los concejales de ambos partidos demuestren que el PER, implica una gran cuota de poder, pero que los dos sectores lo ven como una iniciativa que no debe ser manejada por el gobierno municipal si no que es un bien público de la ciudad. En el diario La Capital del 19 de octubre de 1996 se percibe concretamente el debate en torno al PER para evitar una única reivindicación política del mismo. Si bien el lanzamiento estuvo a cargo de la Intendencia, no es propiedad de la Municipalidad (...) está planteado como una herramienta de gestión de la ciudad ${ }^{11}$. Años después el arquitecto Eduardo Reese, al participar del congreso Internacional Ciudad Futura de 1999, impulsado en el marco del PER, por la Municipalidad de Rosario, hacía referencia indirectamente a lo discutido anteriormente por los concejales rosarinos. Hacer énfasis en que el municipio y el intendente son claves para el proceso, no implica para él, que ellos sean propietarios del mismo, especificando, así, que el PER es un plan de gobierno, y no del gobierno ${ }^{12}$.

Asimismo es importante establecer algunas aproximaciones sobre el modelo barcelonés de planificación para comprender claramente el alcance que logró tener en ciudades latinoamericanas como Rosario. Jordi Borja, al estudiarlo, busca demostrar que cada ciudad debe analizar cuidadosamente el modelo, ya que las particularidades urbanas hacen que, en su opinión, se deba apostar por las diferencias. Barcelona es hoy en el mundo una ciudad deseable ${ }^{13}$, pero esto no implica la copia exacta del modelo. Y yendo aún más lejos el autor se anima afirmar que este conjunto de prácticas ha sido promocionado por el gobierno de la ciudad de Barcelona como un modelo pero que no necesariamente tiene el nivel de coherencia interna que su imagen posterior refleja. Sin embargo fue adoptado por otras urbes debido a la necesidad de acceder a nuevas políticas que les permitieran llevar adelante un accionar acorde a las consecuencias de la globalización. En este marco, no se puede dejar de ver que, a pesar de que el modelo barcelonés haya sido objeto, posteriormente, de fuertes críticas, el PER tiene una vinculación teórica y metodológica directa pero no es una copia exacta del mismo. Algunos de los elementos comunes que identificamos implican, por ejemplo, la fragmentación del territorio para trabajar intensivamente en la zona seleccionada. En el caso rosarino se manifiesta a través de la división en distritos de la ciudad. Conjuntamente se puede mencionar al marketing urbano y a la participación activa de la ciudadanía, como principios reguladores del urbanismo barcelonés, que fueron adaptados a la especificidad territorial rosarina, desde el PER.

Por otro lado, debe comprenderse que el PER, y sus formas posteriores se enmarcan dentro de un proceso de modificación del Estado municipal, en donde la descentralización del poder es clave para su reforma. Para 1995 el diagnóstico que manejaba el municipio establecía que la ciudad había sido objeto de un rápido crecimiento urbano, concentrado en un escaso espacio

\footnotetext{
${ }^{11}$ Comentario realizado por los ediles Piú y Urruty. Cruce de opiniones por el plan estratégico. Diario La Capital, Rosario 19 de octubre de $1996 ; 16$.

12 REESE, 1999; 3.

13 BORJA, 2010; 136.
} 
físico que no abarcaba más de 5 de sus $180 \mathrm{~km} 2$ de superficie ${ }^{14}$ en donde se encontraba el grueso de la actividad comercial, administrativa y empresarial. Esta concentración se daba en el centro y hacía que las diferentes zonas de la ciudad sintieran su lejanía frente a él, como provisor de bienes y servicios, y además se desconocían las problemáticas que afectaban a los otros espacios.

Es frente a esta situación que el municipio comienza a generar cierta descentralización política y administrativa a partir de dos objetivos claros. El primero implicaba un aspecto ideológico que iba unido a la necesidad de generar un gobierno más participativo y cercano a los ciudadanos. El segundo establecía el desarrollo de un nuevo modelo de ciudad más equitativa y equilibrada, generando con ambos la conformación de una democracia más cercana.

Entre las políticas públicas realizadas con tal objetivo, se encuentran el presupuesto participativo o la división de la ciudad en seis distritos, estableciendo en cada uno de ellos centros claves para la realización de trámites, o la adquisición de bienes y servicios públicos que con anterioridad sólo se obtenían en el centro de la ciudad. La ciudad se encuentra organizada en seis distritos, los cuales se han convertido en verdaderos soportes materiales y simbólicos de la gestión pública y de la vida cotidiana de quienes habitan y transitan estos espacios (...) La apuesta para este nuevo ciclo se centra en el objetivo estratégico de profundizar la democracia participativa a nivel de la gestión distrital ${ }^{15}$. Esta frase tomada del PER +10 reafirma la importancia de la descentralización y continua apostando a la misma.

Por último es importante destacar que tanto PER, como el posterior PER +10 , van a implicar el trabajo en conjunto de sectores públicos y privados de inversión. No fue una iniciativa totalmente pública, ya que para mitad de la década de los 90 el municipio no contaba con capital suficiente para desarrollar la totalidad de los proyectos deseados. Además de la inversión privada, hubo una importante cuota de capitales provinciales y nacionales. Así, como puede verse, en la entrevista del diario La Capital del día 29 de octubre de 1998 realizada al secretario municipal Miguel Lifschitz, dos eran sus principales preocupaciones en torno al PER. La primera implicaba la tarea de mantener el control y el seguimiento de los proyectos ya iniciados por la Nación o la Provincia, y la segunda era mantener el interés de los capitales privados en la planificación evitando la desafectación de estos, manifestando que ese fantasma está presente (...) y que muchas instituciones plantearon su preocupación por estar participando de algo que podía ser sólo un ejercicio intelectual ${ }^{16}$.

Como lo demostrará el PER + 10 y su balance a las diez años del primer plan, la inversión privada fue la más cuantiosa. Para conservar su flujo se hizo necesario una acuerdo de intereses entre el municipio y los diferentes tipos de capitales privados, impulsando concesiones concretas de ambos lados, aunque mayores desde la intendencia. La generación de convenios urbanos de tipo públicos - privados para estos proyectos otorgó permisos con amplios márgenes de accionar a las empresas privadas, implicando como contraprestación para el municipio la realización de obras públicas. Por esto, aun hoy, es importante señalar que la dependencia del capital privado, que tiene el gobierno de la ciudad crea un desfasaje entre la creación de una ciudad de y para todos, y su efectiva realización, ya que al intervenir activamente y mayoritariamente este sector, los intereses particulares pasan a jugar un papel central.

\section{PER + 10: un accionar redireccionado}

A primera vista puede divisarse que el documento del PER +10 es mucho mas acotado que el anterior, debido a que el PER ya había sentado las bases teóricas fundamentales, haciendo que

\footnotetext{
14 GHIRARDI, 2000; 3.

15 PLAN ESTRATÉGICO ROSARIO METROPOLITANA 2008 - 2018; 154.

${ }^{16}$ El Plan Estratégico Rosario presenta su documento final. Diario La Capital, Rosario 29 de octubre de 1998 ; 6.
} 
la segunda planificación implique un nuevo diagnóstico y evaluación de la situación urbana, además de una reprogramación del futuro accionar.

EI PER + 10 tiene una doble tarea, que implica mantener lo logrado hasta el momento pero a la vez generar nuevas políticas a partir de una constitución del territorio rosarino como metropolitano. Ambos planes contemplan a Rosario como la cabecera de un área metropolitana, definida como un espacio abierto e interconectado. La Rosario metropolitana es un conglomerado urbano ubicado geográficamente al Sur de la Provincia de Santa Fe, en la zona medular de la República Argentina. Su centro es la ciudad de Rosario.(...) Esta metrópolis se estructura en base a la ciudad cabecera y a un conjunto de comunas y municipios que configuran una realidad urbano - rural, conocida como Área o Región Metropolitana de Rosario ${ }^{17}$.

Esta región está delimitada por dos elementos: 1) la continuidad urbana 2) la interdependencia funcional ${ }^{18}$, es decir, la integración geográfica del área, que implica estrechos vínculos socio económicos. El territorio metropolitano es visto como una estructura compleja, que se define constantemente por la interacción y el conflicto, en un espacio privilegiado donde se desarrollan múltiples relaciones sociales que delinean su identidad ${ }^{19}$.

Aun cuando los dos planes tienen esta conceptualización sobre la ciudad las tareas a realizar se diferencian, ya que la planificación del año 1998 busca entre sus objetivos principales la determinación de un área metropolitana más definida y concreta. Para 1998 se hacía necesario reconocer la extensión del área y comprender como se daban las interacciones entre las comunas y diferentes ciudades en relación con Rosario. Se demandaba la coordinación del accionar de la Nación, provincia y municipio, así como también unión de las políticas privadas y públicas.

En cambio para el año 2008 la tarea será otra. Rosario ha cambiado: se ha convertido en una ciudad metropolitana ${ }^{20}$ lo que nos muestra que la configuración espacial que se buscaba obtener a partir del PER, ha logrado darse 10 años después, aunque no en su totalidad. El PER +10 entiende que se obtuvo un reconocimiento claro del área pero que todavía falta superar las limitaciones propias de la materialización de la planificación, entre las que se nombra la dificultad que genera un plan que va mas allá de los límites políticos, ya que al considerar a la región fuera de estas delimitaciones la ausencia de un marco legal que brinde autonomía de acción a los municipios y comunas se hace central. Debe destacarse que el territorio metropolitano no constituye una unidad a priori ni un producto de la evolución natural de los municipios que lo conforman, sino que se trata de un proceso de construcción social, cuyos factores principales son las estrategias organizativas de sus actores y el tipo de instituciones que lo conforman ${ }^{21}$.

Así el PER + 10 puede ser entendido como un reajuste del accionar a partir de una gestión exitosa que lleva un recorrido de 10 años. Rosario se ha transformado, los lazos complejos que constituyen su dimensión metropolitana se han extendido y consolidado, y las soluciones a los problemas de ayer imponen hoy nuevos retos 22 .

Por último debemos marcar algunas similitudes y diferencias morfológicas entre los dos planes. Ambos se inician con un diagnóstico básico sobre la situación actual de la ciudad, para luego establecer cinco horizontes que expresan objetivos generales a partir de los cuales se van a especificar la misma cantidad de líneas estratégicas de trabajo, cada una desglosada en un conjunto de proyectos específicos. Además se basan en la matriz DAFO, un modelo de análisis empresarial propio de los 90 que implica, por un lado, estudiar debilidades y amenazas internas

17 PLAN ESTRATÉGICO ROSARIO METROPOLITANA 2008 - 2018; 10-12.

18 Op. Cit.; 15.

19 Op. Cit.; 16.

${ }^{20}$ Op. Cit.; 3.

${ }^{21}$ Op. Cit.; 16.

22 Op. Cit.; 36. 
de la institución, y por el otro, fortalezas y oportunidades, del contexto externo. Pero, si bien ambos planes tienen formato de libro, el PER +10 es un documento mucho más específico y mejor diagramado debido a la incorporación de cuadros, estadísticas e imágenes que no poseía el PER.

Una vez comprendidos los puntos centrales de las dos planificaciones pasaremos a concentrarnos en la imagen que específicamente ellos construyen e intentan proyectar sobre la ciudad y la configuración que se hace sobre el espacio público.

\section{El imaginario urbano en los planes estratégicos: la constitución de una ciudad como marca}

A lo largo de su historia Rosario ha generado múltiples imágenes de sí misma que resaltan algún rasgo particular de la ciudad. Sólo algunas de ellas llegaron a tener el nivel aceptación suficiente para ser legitimadas interior como exteriormente. Ejemplo de ellas pueden ser la ciudad sin fecha de fundación, Ciudad - Puerto, hija de su propio esfuerzo, la ciudad inmigrante ${ }^{23}$ o la Chicago Argentina ${ }^{24}$ de principios del siglo XX. Rosario siempre ha buscado espejos donde reflejarse $y$, también, donde inspirarse para construir imágenes de lo que quiere ser o cree que es ${ }^{25}$.

Pues bien, para poder comprender parte de las imágenes construidas en torno a Rosario, deberíamos revisar, en primer lugar, algunas concepciones en torno a los términos ciudad e imaginario urbano.

Para Hiernaux, lo urbano se caracteriza por tres categorías fundamentales: lo laberíntico, lo fugaz y lo fortuito ${ }^{26}$. La ciudad es claramente una metáfora de un laberinto. Entrar en ella implica tener la capacidad de adaptarse, y encontrar una solución diferente a cada camino nuevo que se nos presenta. La complejidad anida en la ciudad y la transforma en un tejido de caminos mentales y físicos que obliga a vaivenes, retrocesos y avances.

La ciudad implica también, velocidad. Lo fugaz se vuelve clave: no permite la lentitud, rechaza la permanencia por lo que la ciudad maldice a quienes no son capaces de seguir sus pautas de fugacidad $^{27}$. Los lazos, antes estables, son ahora efímeros. Además, a la fugacidad de la vida urbana, se le asocia directamente lo fortuito. La ciudad nos ofrece a todo momento posibilidades nuevas en cada esquina, lo que no implica que tenga un funcionar caótico. La ciudad es una cuna de innovaciones porque reúne una multiplicidad de experiencias humanas que, situadas en un sustrato laberíntico, marcado además por la fugacidad de lo que allí ocurre, permite una suerte de combinatoria al infinito de eventos ${ }^{28}$. En esta ciudad, caracterizada a partir del concepto de modernidad líquida ${ }^{29}$, de Zygmunt Bauman, el sujeto está en una vigilia permanente, en una construcción constante de imágenes que es forjada a partir de la velocidad intermitente de la experiencia vivencial diaria.

Por esto, es necesario comprender la noción de imaginario urbano. Para ello comenzaremos por el aporte innegable realizado por Néstor García Canclini. Como especifica en una entrevista que le realizó Alicia Lindón: imaginamos lo que no conocemos, o lo que no es. Lo imaginario corresponde a elaboraciones simbólicas de los que observamos ${ }^{30}$. Si bien lo imaginario es una

23 PLAN ESTRATÉGICO ROSARIO 1998; 43.

24 VERA, 2013; 157.

25 Op. Cit.; 157.

${ }^{26}$ HIERNAUX, 2006; 9.

27 Op. Cit. ; 12.

28 Op. Cit.; 13.

${ }^{29}$ BAUMAN, 2004; 14.

30 LINDÓN, 2007; 90. 
representación de lo vivido, traducido en una imagen mental, va más allá. El imaginario también es el lugar de elaboración de insatisfacciones, deseos, búsqueda de comunicación con el otro ${ }^{31}$.

Lo imaginario no es simplemente una representación, es una fuerza que actúa, que tiene capacidad creativa, una forma que tienen los habitantes para enfrentar su realidad. Por esto, Daniel Hiernaux nos expresa que el imaginario aporta un complemento de sentido a las representaciones, las transforma para ser tanto guías de análisis como guías de acción. Crea imágenes actuantes, imágenes guías, imágenes que conducen procesos ${ }^{32}$.

Cabe aclarar, antes de centrarnos en el análisis del tipo de imágenes que se representan en los planes estratégicos de Rosario, que los imaginarios urbanos son un tipo de imaginarios sociales que no abarcan su totalidad, y que se concentran, solamente, en una clase particular de imaginarios que refleja el entretejido que genera el espacio urbano.

Frente a esto podemos pensar que la imagen es una construcción, es la dimensión simbólica generada por la comunidad sobre sí misma, que establece pautas de acción. Cada comunidad genera múltiples discursos sobre su identidad, manifestados en visiones que luego pueden ser tomadas o encaminadas hacia cierta dirección por la política hegemónica. Para la elaboración de una imagen o marca de ciudad se hace necesario hacer efectivas proyecciones de idealizaciones tanto hacia el pasado como hacia el futuro. Surge, entonces la necesidad de hacer uso del marketing urbano que considera a la ciudad como nueva mercancía cuya marca distintiva elaborada a partir de un imaginario dominante debe ser proyectada exteriormente.

Ahora bien, ¿qué tipo de imágenes son proyectadas en los planes estratégicos? ¿Hacia dónde se quiere encaminar a la ciudad a partir de ellas? En ambos planes se establecen representaciones dominantes sobre el pasado, presente y futuro, modelando la marca de la urbe que se busca construir. La imagen de una ciudad va producir significados y definir actividades mediantes las cuales se determinará la construcción el espacio público y su utilización. En el modelo de ciudad convergen aspectos imaginarios que orientan decisiones y materializaciones ${ }^{33}$. Es por esto que el perfil urbano que establece el PER está determinado por la idea de una ciudad de cara al río, presentando a la zona costera como un corredor estratégico, como lo marca específicamente en la fundamentación de la línea estratégica IV, La ciudad del río:

Integrar la ciudad y el río, potenciando un espacio de transformaciones que sintetice una nueva imagen urbana ${ }^{34}$.

La integración ciudad - río implica para esta planificación la apertura del área ribereña a través de espacios públicos como parques, avenidas o paseos, con proyectos como la extensión norte del Parque España ya existente en 1998 o la reorganización del espacio en el Parque a la Bandera, ambos ubicados en la zona costera.

Este proceso de composición de la ciudad de cara al río se comprende debido al traslado de sectores portuarios hacia otros centros de producción o hacia sectores más alejados del centro de la ciudad. Se generaron grandes porciones espaciales vacías que fueron vistos para fines de los 90 como garantías de acceso directo al río creando un renovado interés del gobierno municipal por estos. Es así que estos tramos ahora libres buscan ser reorganizados en torno a una multiplicidad de actividades, sobre todo culturales y sociales, para asegurar la accesibilidad a la costa de todos los ciudadanos.

\footnotetext{
31 Op. Cit. ; 93.

32 HIERNAUX, 2007; 20.

33 VERA, 2013; 155.

34 PLAN ESTRATÉGICO ROSARIO 1998; 85.
} 
Por otro lado, el PER + 10 asume desde sus inicios que el cambio de eje de la ciudad para orientarla hacia el río, fue producido en esos 10 años de trabajo. Si bien profundiza esta imagen, se centra, más concretamente, en la nueva movilidad inter e intra distrital y regional. El PER tuvo como base una oscilación centro-periferia que debía ser cambiada, y que, en cambio el PER + 10, logró modificar en parte.

Como venimos viendo el contexto de surgimiento de los planes es un proceso de descentralización del poder municipal, que implica generar el derecho a la ciudad para todos ${ }^{35}$. Como respuesta a esta problemática el geógrafo español, Jordi Borja establece a la constitución de nuevos tejidos urbanos como la manera más optima para generar esa condición de ciudad equitativa. Estos, son tramas que constituyen y configuran los espacios urbanos, específicamente al espacio público. En la ciudad lo primero son las calles y plazas, los espacios colectivos, después vendrán los edificios y las vías. El espacio público define la calidad de la ciudad, porque indica la calidad de la vida de la gente y la calidad de la ciudadanía de sus habitantes ${ }^{36}$. El espacio público debe ser considerado ordenador del urbanismo ya que en él confluye la vida cotidiana de los ciudadanos. En sus formas diversas se da la reunión de los extraños, unidos por aquello que genera las diferencias: el distanciamiento y el anonimato. Las ciudades son espacios donde los extraños permanecen y se mueven en estrecha y mutua proximidad ${ }^{37}$. Por esto establecer en el espacio público fronteras simbólicas que delimiten su uso y apropiación, forma parte del imaginario de ciudad que buscan proyectar los planes estratégicos.

Aún cuando las planificaciones trabajen exhaustiva y detalladamente el camino que desean seguir para llegar a una conformación determinada de la ciudad, nunca debemos dejar de lado la demostración que nos hace la realidad en torno al espacio público. Es el usuario del mismo quien va a hacer efectivo o no, el objetivo a partir del cual se organizó a ese espacio. Los ciudadanos viven y conviven en la trama urbana de manera subjetiva, expresando sus opiniones a través de las formas de uso de los sitios. La planificación iba encaminada en cierta dirección, pero al hacer uso del lugar, los usuarios y habitantes resignifican esa zona desde otro punto de vista. Esto no quiere decirnos que los planes urbanos no hayan logrado sus objetivos, si no que son márgenes de posibilidades que pueden darse.

A modo de ejemplificación se puede establecer como caso paradigmático la construcción del Parque Independencia a principios del s. XX, en Rosario. Este parque fue pensado a partir de varias visiones que marcaron su surgimiento. El historiador Diego Roldán en su libro La invención de las masas, nos muestra que este tuvo varias finalidades, comentando que la ordenanza que determinaba su construcción le otorgaba múltiples funciones, desde higiénicas, económicas a simbólicas y políticas. El parque era imaginado como un dispositivo comunitario, capaz de atenuar cualquier diferencia socia/38. Fue un mecanismo central que se pensó originalmente para los sectores populares, remarcando sus funciones sanitarias. Pero los usos sociales que se le otorgaron de manera inmediatamente posterior demostraron una preferencia por la configuración elitista y lo signaron como medio de diferenciación social. A pesar de ello, el posterior proceso de nacionalización del espacio verde que implicó la consolidación de una multiplicidad de plazas en la ciudad, produjo una popularización y masificación del parque Independencia concretando el objetivo por el cual había surgido.

Este desfasaje entre los objetivos de la planificación, y la utilización efectiva del espacio público se produce debido a que las experiencias personales de cada uno de los habitantes que transitan por ellos son, justamente, individuales, y establecen en él, múltiples dimensiones. Por eso, la

35 BORJA, 1999; 7.

${ }^{36}$ BORJA, 2010; 135.

37 BAUMAN, 2013; 140.

38 ROLDÁN, 201; 87. 
multidimensionalidad del espacio urbano comenzó a ser vista de a poco por los planificadores, obligándolos, necesariamente, a considerar a los imaginarios urbanos en sus proyecciones espaciales a futuro. Como nos menciona Josep V. Boira Maiques, existe un espacio vivido que es descrito a través del prisma de la experiencia personal de la gente, coloreada por sus esperanzas y miedos y distorsionada por prejuicios y predilecciones ${ }^{39}$. Este autor, al concentrarse en los nuevos desafíos de la planificación urbana, nos brinda una serie de herramientas a través de las cuales fomenta la construcción de programas urbanísticos, desde el ciudadano que vive diariamente en la ciudad, y no sobre él. El arquitecto planificador puede obtener información totalmente nueva de los ciudadanos, concentrándose en las vivencias próximas a sus entornos de vida concretos, para lograr, a través de ello, incorporar una micro realidad y construir, desde allí, un macro espacio. A partir de ideas como las de Boira Maiques, podemos entender la importancia que comenzaron a tener los imaginarios urbanos en las formas de organización del espacio. Los nuevos desafíos implican métodos que indagan sobre la propia esencia del espacio, caracterizado por los vecinos implicados.

Los diversos modos de habitar en la ciudad nos demuestran los imaginarios que representan a los sujetos sociales de diferentes grupos. Como nos muestran Lindón y Hiernaux, la heterogeneidad imaginaria está asociada a los puntos de vista de los diversos grupos sociales de una ciudad ${ }^{40}$. Así, la forma de usar o practicar la ciudad puede ser vista desde el accionar individual, como lo hace Boira Maiques, o desde la diversidad que también generan los múltiples grupos sociales, como lo ven Lindón y Hiernaux. Pero estas visiones no son contrapuestas, ya que entendemos que los imaginarios urbanos, forman parte de la subjetividad tanto individual como colectiva.

Frente a estas formas interpretativas, lo que se hace certero es que, como lo demuestra García Canclini, se da la coexistencia de múltiples culturas en un espacio que llamamos urbano ${ }^{41}$, una diversidad de ciudades de suceden en el mismo suelo, estableciendo uno de los principales obstáculos para quienes intentan organizarla. Una ciudad siempre es heterogénea, porque hay muchos imaginarios que la habitan ${ }^{42}$.

A pesar de la diversidad urbana existe un imaginario dominante que es visto como principal a la hora de constituir límites organizacionales en la ciudad. Los imaginarios dominantes, como lo resaltan Alicia Lindón y Daniel Hiernaux, son imaginarios actantes ${ }^{43}$, que dominan a las decisiones tomadas para los modelos urbanos de las sociedades contemporáneas. Aun cuando la multiplicidad de imaginarios sea característica de la vivencia en la ciudad, es importante entender que los planes estratégicos, en este caso para Rosario, van concentrarse en los imaginarios dominantes, para construir desde ellos el modelo de metrópoli a lograr.

Por último, podemos hacer extensivo al espacio público en general el planteo que hace Delgado Ruiz en su libro Ciudad líquida, Ciudad interrumpida, sobre las plazas y la calle. En él, nos comenta que ambos espacios son objeto de un doble discurso. El primero es resultado de una planificación, diseño urbanístico y arquitectónico que está determinado políticamente y que busca influir sobre las estructuras relacionales de los usuarios del espacio ${ }^{44}$. El otro se caracteriza por ser el de los usuarios de lo urbano. Son ellos quienes tienen la última palabra acerca de cómo y en qué sentido moverse físicamente en el seno de la trama propuesta por los diseñadores ${ }^{45}$,

39 BOIRA MAIQUES, 2008; 248.

40 LINDÓN; HIERNAUX, 2007; 161.

41 GARCÍA CANCLINI, 1997; 78.

42 LINDON, 2007; 91.

43 LINDON; HIERNAUX, 2008; 8.

44 DELGADO RUIZ, 1999; 17.

45 Op. Cit.; 18. 
dejando de lado, muchas veces a los imaginarios dominantes a partir de los cuales de organizó el espacio.

\section{Reflexiones finales}

Rosario ha sido considerada desde una variada gama de imágenes que buscan trazar el camino a seguir en el desarrollo de la ciudad. En el surgimiento de una visión de la ciudad, la comunidad que la integra tiene un papel central. Si bien es ella quien constituye múltiples miradas sobre lo urbano, el sector político será el encargado de retomarlas, darles límites finos y producir la imagen que mayor provecho pueda generar tanto para la ciudad misma como para la clase dirigente en sí misma, ya que no podemos pensar que la dirección de una visión no implica intrínsecamente intereses políticos. Luego de un proceso de construcción de objetivos determinados desde un imaginario dominante, en el caso de los dos planes estratégicos, la visión delimitada establece pautas relacionales con el pasado y futuro, y es efectivizada en la realidad a través de la concreción de espacios públicos encaminados a tal fin. Este, pasa a ser una especie de prueba en donde se logran o no consolidar esas visiones urbanas en los habitantes de la ciudad. Tanto el PER, como el PER + 10, buscaron desde un primer momento construir una idea urbana que tenía como eje al río, dejando de lado viejas formas de organización del espacio, construyendo una multiplicidad de espacio públicos para asegurar el acceso a la ribera de una gran cantidad de habitantes. Asimismo generaron nuevas formas de acceso a la política a través de la descentralización del municipio y la creación de distritos o presupuestos participativos, que implico un reacomodamiento de las relacionales espaciales, haciendo que el PER + 10 deba concentrarse más en comprender este nuevo tipo de movilidad generada en el curso de 10 años.

Pero esto no significa que todas las proyecciones realizadas a través de las planificaciones estratégicas sean realizadas efectivamente en la realidad. Como ya hemos mencionado son los usuarios de los espacios públicos quienes van a concretar dicha planificación pudiendo ser su accionar acorde o no a ella. Las planificaciones son guías a seguir lo que no implica que sean el único camino posible.

Además, cabe aclarar que pueden existir múltiples factores tanto internos como externos que modifiquen la visión que se desea proyectar sobre la ciudad, entre los que los medios de comunicación son muy importantes. Ellos pueden perjudicar o favorecer al establecimiento de una imagen legítima y particular. Es por esto que la clase política se concentra específicamente en el establecimiento de ciertas visiones urbanas, ya que una vez arraigada una de ellas, su cambio implicará un proceso de trabajo largo y arduo.

Frente a todo lo estudiados, nos parece interesante preguntarnos cuáles serán los caminos que tomarán las futuras planificaciones rosarinas, ya que el PER +10 puede darnos algunos indicios sobre los nuevos lineamientos que el gobierno municipal podría llegar a profundizar. Una vez establecida como metrópolis ¿cuáles serán las próximas políticas a desarrollar en la ciudad? ¿Qué medios lograran mantener los vínculos ya establecidos en el nuevo espacio regional? ¿Cómo se logrará romper con el desfasaje que se produce entre la planificación y la utilización de los espacios púbicos?

Estas y muchas preguntas más, son disparadoras de nuevas interpretaciones que pueden realizarse sobre los planes estratégicos de Rosario analizando algunos de los múltiples lineamientos que estos abren. Así, solamente nuevos desarrollos urbanos podrán confirmar o refutar algunas de respuestas que hemos obtenido para los cuestionamientos iniciales con los que nos acercamos a la temática.

\section{Bibliografía}




\section{Fuentes}

Municipios como agentes promotores del cambio. Diario La Capital, Rosario, 7 de julio de 1995. Pp. 15.

Cruce de opiniones por el plan estratégico. Diario La Capital, Rosario, 19 de octubre de 1996. Pp. 16.

El Plan Estratégico Rosario presenta su documento final. Diario La Capital, Rosario, 29 de octubre de 1998. Pp. 6.

EI PER apunta a fortalecer el rol de Rosario en el Mercosur. Diario El Ciudadano, Rosario, 30 de octubre de 1998. Pp. 2.

Planificación y gestión en el encuentro Ciudad Futura. Diario La Capital, Rosario, 9 de mayo de 2000. Pp. 9.

Presentaron los ejes del Plan Estratégico. Diario La Capital, Rosario, 4 de abril de 2008. Pp. 7.

Buen Saldo de Planificación. [En línea] Diario El Ciudadano, Rosario, 28 de abril de 2010. [Fecha de consulta: mayo de 2014] Disponible en: http://www.elciudadanoweb.com/buen-saldo-deplanificacion/

\section{Planes Estratégicos}

PLAN ESTRATÉGICO ROSARIO 1998. [En línea] Municipalidad de Rosario. [Fecha de consulta: mayo de 2014] Disponible en: http://www.perm.org.ar/per98/per_98.pdf

PLAN ESTRATÉGICO ROSARIO METROPOLITANA 2008 - 2018. [En línea] Municipalidad de Rosario. [Fecha de consulta: mayo de 2014] Disponible en: http://www.perm.org.ar/Perm-libro.pdf

\section{Libros y artículos}

BAUMAN, Zygmunt. Sobre la dificultad de amar al prójimo. En: BAUMAN, Zygmunt. Amor líquido. Acerca de la fragilidad de los vínculos humanos. Decimoquinta edición. Buenos Aires, Argentina, Fondo de Cultura Económica. Junio de 2013. Pp. 105-154. ISBN 978-950-557-648-7.

BAUMAN, Zygmunt. Prólogo. Acerca de lo leve y lo líquido. En: BAUMAN, Zygmunt. Modernidad Líquida. Tercera edición. Buenos Aires, Argentina, Fondo de Cultura Económica. Junio de 2004. Pp. 7-20. ISBN 950-557-513-0.

BOIRA MAIQUES, Josep Vicent. La imagen de la ciudad en la planificación y la política urbana. [En línea] Iztapalapa (64- 65. Año 29): 233-255, División de Ciencias Sociales y Humanidades. Universidad Autónoma Metropolitana. Enero - diciembre de 2008. ISSN 0185-4259. [Fecha de consulta: septiembre de 2014] Disponible en:

http://tesiuami.uam.mx/revistasuam/iztapalapa/include/getdoc. php?id=1611\&article=1658\&mode=pdf

BORJA, Jordi. Urbanismo entre el espacio público y los proyectos - objetos. En: BORJA, Jordi. Luces y sombras del urbanismo de Barcelona. Segunda edición. Buenos Aires, Argentina, El Café de las Ciudades. Octubre de 2010. Pp. 135-161. ISBN 978-84-9788-901.

BORJA, Jordi. Los desafíos del territorio y los derechos de la ciudadanía. [En línea] En: Seminario internacional: El renacimiento de la cultura urbana. Frente a la Globalización: Ciudades con Proyecto. (No I, 29 y 30 de junio de 1999, Rosario). Seminario Internacional: El renacimiento de la cultura urbana. Rosario, Argentina. Municipalidad de Rosario. 1999. Pp. 1-28. [Fecha de consulta: septiembre de 2014] Disponible en: http://www.perm.org.ar/biblioteca/articulos/dlos_desafios_del_territorio....pdf

DELGADO RUIZ, Manuel. La ciudad no es lo urbano. En: DELGADO RUIZ, Manuel. Ciudad líquida, ciudad interrumpida. Colección Estética Expandida. Medellín, Colombia, Editorial Universidad de Antioquia. Universidad Nacional de Colombia. Marzo de 1999. Pp. 1-19. ISBN 10 958-65-533-29. 
GARCÍA CANCLINI, Néstor. ¿Qué es una ciudad? En: GARCÍA CANCLINI, Néstor. Imaginarios Urbanos. Serie Aniversario. Colección Pensamiento Contemporáneo. Buenos Aires, Argentina, Editorial Universitaria de Buenos Aires. Eudeba. Universidad de Buenos Aires. Agosto de 1997. Pp. 69-97. ISBN 950-23-0670-8.

GHIRARDI, Horacio. Descentralización y Participación ciudadana, ejes de una gestión moderna y solidaria. [En línea] En: Curso Internacional Ciudad Futura (No II, mayo de 2000, Rosario). II Curso Internacional Ciudad Futura. Rosario, Argentina. Municipalidad de Rosario. 2000. Pp. 1-10. [Fecha de consulta: septiembre de 2014] Disponible en: http://www.perm.org.ar/biblioteca/articulos/ddescentralizacion_y_participacion_ciudadan.pdf HIERNAUX, Daniel. De los imaginarios a las prácticas urbanas: construyendo la ciudad de mañana. [En línea] Iztapalapa (64- 65. Año 29): 15-35, División de Ciencias Sociales y Humanidades. Universidad Autónoma Metropolitana. Enero - diciembre de 2008. ISSN 0185-4259. [Fecha de consulta: septiembre de 2014] Disponible en:

http://tesiuami.uam.mx/revistasuam/iztapalapa/include/getdoc.php?id =1602\&article $=1648 \& \mathrm{~m}$ ode $=$ pdf

HIERNAUX, Daniel. Los imaginarios urbanos: de la teoría y los aterrizajes en los estudios urbanos. [En línea] Eure (XXXIII. No 99): 17-30, Pontificia Universidad Católica de Chile. Agosto de 2007. ISSN 07176236. [Fecha de consulta: septiembre de 2014] Disponible en: http://www.redalyc.org/articulo.oa?id=19609903

HIERNAUX, Daniel. Repensar la ciudad: La dimensión ontológica de lo urbano. [En línea] Liminar. Estudios Sociales y Humanísticos (Vol 4, No 002): 7-17. Universidad de Ciencias y Artes de Chiapas. Diciembre de 2006. ISSN 1665-8027. [Fecha de consulta: septiembre de 2014] Disponible en:

http://www.redalyc.org/pdf/745/74540202.pdf

LINDÓN, Alicia; HIERNAUX, Daniel. Los imaginarios urbanos de la dominación y la resistencia: un punto de partida. [En línea] Iztapalapa (64- 65. Año 29): 7-12, División de Ciencias Sociales y Humanidades. Universidad Autónoma Metropolitana. Enero - diciembre de 2008. ISSN 0185- 4259. [Fecha de consulta: septiembre de 2014] Disponible en:

http://tesiuami.uam.mx/revistasuam/iztapalapa/include/getdoc.php?id=1601\&article=1647\&m ode $=$ pdf

LINDÓN, Alicia. Diálogo con Néstor García Canclini. ¿Qué son los imaginarios y cómo actúan en la ciudad? [En línea] Eure (XXXIII. No 99): 89-99, Pontificia Universidad Católica de Chile. Agosto de 2007. ISSN 0717-6236. [Fecha de consulta: septiembre de 2014] Disponible en: http://www.redalyc.org/articulo.oa?id=19609908

LINDÓN, Alicia; HIERNAUX, Daniel. Imaginarios urbanos desde América Latina. Tradiciones y nuevas perspectivas. En: SILVA CARVALHO, Armando (Director). Imaginarios urbanos en América Latina: urbanismos ciudadanos. Barcelona, España, Fundación Antoni Tàpies. Mayo de 2007. Pp. 157-167. ISBN 978-84-88786-28-9.

POLIMENE, María Paula. Ideas globales, problemas locales. Intercambio de experiencias y conceptos sobre el gobierno de la ciudad de Rosario, fines del siglo XX. [En línea] Avances del Cesor (6): 81-99, Facultad de Humanidades y Artes. Universidad Nacional de Rosario. Septiembre de 2009. ISSN No 1514-3899. [Fecha de consulta: junio de 2014] Disponible en: http://www.ishir-conicet.gov.ar/avances.php

REESE, Eduardo. Planes estratégicos: limitaciones y oportunidades. [En línea] En: Curso Internacional Ciudad Futura (No I, mayo de 1999, Rosario). I Curso Internacional Ciudad Futura. Rosario, Argentina. Municipalidad de Rosario. 1999. Pp. 1-6. [Fecha de consulta: septiembre de 2014] Disponible en:http://www.perm.org.ar/biblioteca/mediateca-articulos.php 
ROLDÁN, Diego Pablo. La invención de las masas. Ciudad, corporalidades y culturas. Rosario, 1910 1945. Buenos Aires, Argentina, Prohistoria Ediciones. Noviembre de 2012. 246 p. ISBN 978-950-34-09008.

SMITH, Neil. ¿Ciudades después del neoliberalismo? [En línea] En: SMITH, Neil; Observatorio Metropolitano; ROLNIK, Raquel; ROSS, Andrew; DAVIS, Mike. Después del Neoliberalismo: ciudades y caos sistémico. Madrid, España, MACBA. 2009. Pp. 9-30. ISBN 978-84-92505-11-1. [Fecha de consulta: junio de 2014] Disponible en: http://www.macba.cat/PDFs/neilsmith.pdf

SOJA, Edward W. Postmetrópolis. Estudios críticos sobre las ciudades y las regiones. Madrid, España, Traficantes de Sueños Ediciones. Noviembre de 2008. 598 p. ISBN 13: 978-84-96453-32-6.

VERA, María Paula. Imaginarios urbanos y procesos de urbanización en las nuevas ciudades turísticas. EI caso de la ciudad de Rosario, Argentina. [En línea] Revista Bitácora (22-1): 153-162. Universidad Nacional de Colombia. Junio de 2013. ISSN: 2027-145. [Fecha de consulta: mayo de 2014] Disponible en: http://www.revistas.unal.edu.co/index.php/bitacora/issue/view/3419/showToc 